\title{
PREDICTING UNDERGRADUATE STUDENT OUTCOMES: COMPETING OR COMPLEMENTARY ROLES OF SELF-ESTEEM, SELF-COMPASSION, SELF-EFFICACY, AND MINDSETS?
}

\author{
\begin{tabular}{c|c|c} 
LOUISE WASYLKIW & SOPHIE HANSON & LAURENCE MACRAE LYNCH \\
MOUNT ALLISON UNIVERSITY & MOUNT ALLISON UNIVERSITY & MOUNT ALLISON UNIVERSITY
\end{tabular} \\ \begin{tabular}{c|c} 
ELISE VAILLANCOURT & CHELSEA WILSON \\
MOUNT ALLISON UNIVERSITY & MOUNT ALLISON UNIVERSITY
\end{tabular}
}

\begin{abstract}
Several individual differences have been shown to predict academic and psychological outcomes among university students, however, it is not always clear which are most impactful, in part because many of the constructs overlap. Thus, the purpose of the present study was to examine the unique contributions of self-esteem, self-compassion, self-efficacy, and mindsets when predicting outcomes among university students. Undergraduate students $(N=214)$ completed an online survey including measures of the predictors as well as the outcomes of self-control, mental health, and both course and term grades. Correlations confirmed the overlap among the predictors highlighting the importance of examining the unique contributions of each. Results of multiple regression analyses showed that self-esteem and self-compassion explained unique variance in depression and anxiety over and above self-efficacy and growth mindsets. In contrast, self-efficacy and growth mindsets each significantly predicted self-control when controlling for self-esteem and self-compassion. Only self-efficacy predicted course grades. Given our results, we suggest that self-compassion and one's beliefs about their abilities are complementary strengths for students attending university and should be considered when designing interventions to improve outcomes. Keywords: self-esteem, self-compassion, self-efficacy, mindsets, self-control, mental health, grades
\end{abstract}

\section{Résumé}

Il a été démontré que plusieurs différences individuelles prédisaient les résultats académiques et psychologiques des étudiants universitaires. Cependant, il n'est pas toujours facile de savoir quelles sont les différences qui ont le plus d'impact, en partie parce que de nombreux construits psychologiques se chevauchent. Ainsi, le but de cette étude était d'examiner les contributions uniques de l'estime de soi, de l'autocompassion, de l'auto-efficacité et de l'état d'esprit lors de la prédiction des résultats chez les étudiants universitaires. Des étudiants de premier cycle $(N=214)$ ont rempli un sondage en ligne comprenant des mesures des prédicteurs ainsi que des résultats concernant le contrôle de soi, la santé mentale et les notes obtenues aux cours et pour le trimestre. Des corrélations ont confirmé le chevauchement entre les prédicteurs, soulignant ainsi l'importance d'examiner les contributions uniques de chaque prédicteur. Les résultats des analyses de régression multiple ont indiqué que l'estime de soi et l'autocompassion expliquaient la variance unique de la dépression et de l'anxiété au-delà de l'état d'esprit quant à l'auto-efficacité et au développement. En revanche, les variables de l'état d'esprit quant à l'auto-efficacité et au développement ont chacune prédit significativement le contrôle de soi en contrôlant pour l'estime de soi et l'autocompassion. II n'y a que l'auto-efficacité qui a prédit les notes aux cours. Étant donné nos résultats, nous suggérons que, pour les étudiants universitaires, l'autocompassion et les croyances de l'individu quant à ses habiletés sont des forces complémentaires qui doivent être considérées dans la conception d'interventions bénéfiques.

Mots-clés : estime de soi, autocompassion, auto-efficacité, états d'esprit, contrôle de soi, santé mentale, notes 


\section{Introduction}

Researchers and clinicians alike increasingly focus on individual strengths that may help people face the challenges they experience in everyday life. For young adults attending university, this is an important direction because of the unique stressors associated with navigating the social and academic demands of postsecondary education. Indeed, up to $31 \%$ of university students in the Maritime Provinces of Canada fail to graduate (Maritime Provinces Higher Education Commission [MPHEC], 2018). Moreover, university students, as young adults between the ages of 15 and 24 years, have the highest rates of mood and anxiety disorders in Canada (Pearson et al., 2013). Whereas several individual differences predict academic and psychological outcomes among university students, it is not always clear which are most impactful, in part because many of the constructs overlap. Thus, the purpose of the present study was to examine the unique contributions of self-esteem, self-compassion, self-efficacy, and mindsets when predicting outcomes among university students.

University is often portrayed as an exciting time in which students enjoy independent living and the academic focus on subjects which are of interest to them. However, not every student is equipped to be successful and a sizable literature highlights skills and strategies that increase the likelihood of academic success. For example, research shows that successful students attend classes (e.g., Dey, 2018); manage their time (e.g., Razali et al., 2017); and use active learning strategies (e.g., Sanitchai \& Thomas, 2018). Nevertheless, university students must forge social relationships and adjust to different living arrangements resulting in a predisposition to experience poorer physical (e.g., Adams et al., 2008) and mental health (e.g., Ibrahim et al., 2013) which may, in turn, threaten academic success (e.g., Andrews \& Wilding, 2004). Therefore, we focused on factors that are known predictors of academic success and mental health.

\section{Predictors}

Research documents the benefits of holding a positive evaluation of one's self (i.e., high self-esteem) (Rosenberg, 1965). For university students, having high self-esteem was associated with better grades and adjustment to college (e.g., Weisskirch, 2018). Although there is a positive association between self-esteem and academic performance, some researchers argue that this relationship is, at best, weak (e.g., Zeigler-Hill et al., 2013). Others maintain that self-esteem does not lead to academic success, rather, self-esteem results from achievement (Baumeister et al., 2003). Still others propose that this relationship operates cyclically whereby self-esteem contributes to behaviours that enhance or undermine academic performance which, in turn, increase or decrease self-esteem (e.g., Swann et al., 2007). The nature of the relationship between self-esteem and mental health is similarly debated, however, the associations between low self-esteem and depression and anxiety are strong (Sowislo \& Orth, 2013). Regardless of the exact nature of the relationship between self-esteem and outcomes, it was included here because of the robust relationships uncovered in past research.

Although having high self-esteem has generally been shown to be beneficial, pursuing high self-esteem has negative consequences. Crocker and Park (2004) cogently argued and outlined research to show that people often engage in maladaptive strategies to achieve or maintain high self-esteem such as taking less responsibility, disregarding negative feedback, demeaning others, or becoming aggressive. In response to growing criticism of self-esteem (e.g., Baumeister et al., 2003), Neff (2003a, 2003b) proposed an alternative construct that captures the benefits of self-esteem without the negative consequences (Neff \& Vonk, 2009). Self-compassion is an attitude towards one's self that is beneficial when one is experiencing hardship or suffering as it involves kindness, care, and understanding (Neff, 2003a). Self-compassion is robustly related to less depression, anxiety, and the experience of stress as seen in correlational (e.g., MacBeth \& Gumley, 2012; Zessin et al., 2015) and experimental investigations (e.g., Neff \& Germer, 2013). University students high in self-compassion viewed disappointing grades in a more positive light (Allen \& Leary, 2010) and were more intrinsically motivated to achieve mastery (e.g., Neff et al., 2005). Although Neff (2003a) theorized that self-compassion differs from self-esteem, these constructs significantly overlap (e.g., Neff \& Vonk, 2009).

A third construct that moderately correlates with both self-esteem and self-compassion is self-efficacy (e.g., de Souza \& Hutz, 2016) where self-efficacy refers to the belief that one is capable of a behaviour or able to attain a goal (Bandura, 1977). Individuals high in self-efficacy 
were theorized to be more likely to approach and persist at behaviours, and subsequently, more likely to succeed (Bandura, 1977, 1997). In a meta-analysis, Moulton et al. (1991) found that self-efficacy accounted for a substantial portion of variance in academic performance and persistence. This has been corroborated by a more recent meta-analytic investigation across 109 samples (Robbins et al., 2004).

The final predictor examined was mindsets. Mindsets refer to implicit theories about the malleability of attributes such that a person with a growth mindset (i.e., incremental theorist) believes that personal attributes can be developed and a person with a fixed mindset (i.e., entity theorist) believes that such attributes are fixed at birth (Yeager \& Dweck, 2012). Adopting a growth mindset appears to set the stage for success such that one is motivated to learn and master material regardless of failures (Dweck \& Leggett, 1988). Middle school students with a growth mindset were more likely to enroll in challenging courses (e.g., Romero et al., 2014), were more academically engaged (e.g., Bostwick et al., 2017), and had higher grades (Claro et al., 2016). There is less research on mindsets in university students, however, the findings appear to be robust across populations. Among first year university students, having a growth mindset was associated with willingness to take a remedial course following poor performance (Hong et al., 1999), and expending more studying effort ( Sriram, 2014). Additionally, having a growth mindset was related to well-being (e.g., Passmore et al., 2018; Romero et al., 2014) and social integration in university (Zander et al., 2018). Interestingly, being self-compassionate was associated with mastery goals and intrinsic motivation, key aspects of having a growth mindset (Neff et al., 2005).

The four constructs outlined were deliberately chosen for the present investigation for two reasons. First, including self-esteem and self-compassion was considered important because they both reflect positive self-attitudes, both relate to the outcomes of interest, and both significantly overlap. However, self-esteem is a global construct that involves evaluations of self-worth whereas self-compassion is most beneficial when one considers their inadequacies or failures and does not entail evaluations of one's self (Neff \& Vonk, 2009). Second, we included self-efficacy and mindsets because they both reflect beliefs and both have been shown to be linked to positive academic behaviours, and, to a lesser extent, mental health outcomes. However, they differ be- cause self-efficacy is akin to confidence in one's self and, in contrast, mindsets, are beliefs about the ability to change.

Up to this point, we have defined four constructs that are associated with academic and mental health outcomes, what remains unclear is the unique contributions of each. Because there is considerable overlap among them, it is difficult to discern if one outperforms the others for specific outcomes. Academic institutions implement initiatives and programs to help students succeed in coursework, complete their degree programs, manage stress, and maintain mental health; however, administrators and faculty need to consider what attributes would lead to the outcomes of interest and the evidence of their effectiveness. One outstanding question concerns whether these constructs are competing or complementary strengths for outcomes that capture success in university including self-control, mental health, and grades.

\section{Outcomes}

Self-control is the capacity to regulate behaviours, thoughts, and emotions to attain a goal that is either short term (e.g., achieving an A on tomorrow's test) or long term (e.g., graduating) (Carver \& Scheier, 2011; Vohs \& Baumeister, 2004). For example, in preparing for a test, students must set aside time to study and decline social opportunities to devote time to studying (i.e., behaviour regulation) as well as manage their anxiety over performance (emotion regulation). Longitudinal research with grade eight students found that self-control explained a significant amount of variance in high school GPA (Duckworth \& Seligman, 2005). In their meta-analysis, de Ridder et al. (2012) showed that self-control was also important for college and university students. Students with high self-control were less likely to procrastinate (e.g., Steel, 2007), had adaptive time management skills (Misra \& McKean, 2000), and were not derailed by distractions (Tangney et al., 2004). Furthermore, some researchers like Tangney et al. (2004) found that self-control predicted grades. The evidence corroborates the claim that the ability to regulate one's self has non-trivial consequences in the context of university and involves skill sets that facilitate success.

We also focused on mental health as an outcome because rates of depression were estimated to be three times as high in university students as in the general population (Ibrahim et al., 2013), and almost $50 \%$ of 
undergraduate students reported moderate to severe anxiety (Bayram \& Bilgel, 2008). Both depression and anxiety are associated with negative academic outcomes including lower grades (e.g., Anson et al., 1984; Hysenbegasi et al., 2005) and dropout (e.g., Hjorth et al., 2016). Students also experience high levels of stress, further exacerbating successful adaptation and academic success (e.g., Wilks \& Spivey, 2010). Finally, we included grades as an outcome because they are a relatively objective index of students' success.

\section{Overview of the present investigation}

By recruiting university students to complete an online survey, we aimed to uncover the unique contributions of self-esteem, self-compassion, self-efficacy, and growth mindsets for predicting self-control, mental health, and grades. To capture students' self-regulatory skills, we included a general index of self-control and persistence as well as a specific index of academic self-control and emotional self-control. For mental health, we included measures to assess depression, anxiety, and stress as well as more positively valanced scales of general well-being. We first hypothesized significant correlations among the predictors demonstrating overlap among self-esteem, self-compassion, self-efficacy, and mindsets. We also hypothesized that all the predictors would be associated with the outcomes of self-control, mental health, and grades. Thus, zero order correlations would demonstrate patterns previously shown in the literature. However, using multiple regression analyses including all predictors, we aimed to uncover the unique contributions of each for predicting outcomes.

\section{Method}

\section{Participants and Procedure}

Following approval from the institution's research ethics board, undergraduate students enrolled in Introductory Psychology in the first four weeks of the academic year were invited to complete an online survey. Initially, 219 students accessed the survey and received course credit for their participation. Four attention checking items were randomly placed within the survey and, at the end of the survey, participants were asked if the responses they gave were trustworthy. Data from three participants who either incorrectly responded to the attention checks or indicated that their responses were not trustworthy were deleted. Data from two additional participants were deleted as they failed to answer any questions beyond demographics.

The final sample comprised 214 students $\left(M_{\text {age }}=\right.$ 19.31 years, $S D=2.37$ ) with $67.3 \%$ identifying as female $(n=144), 32.2 \%$ as male $(n=69)$ and one person who failed to indicate their gender. Of the 211 participants who indicated ethnicity, the majority were Caucasian ( $n=179 ; 85 \%$ ) with others indicating Asian ethnicity ( $n=15 ; 7 \%)$, Black/African Canadian $(n=6 ; 2.8 \%)$, Mixed/Biracial $(n=6 ; 2.8 \%)$ or First Nations/Indigenous $(n=4 ; 1.9 \%)$. Most participants were in their first $(n=$ $142 ; 66.4 \%)$ or second $(n=45 ; 21 \%)$ year of university with the remainder $(n=27 ; 12.6 \%)$ in third, fourth, or fifth year. Following informed consent, participants completed the measures and were then provided with feedback.

\section{Materials}

\section{Demographic Information}

Using open ended questions, participants were asked to indicate their gender, birth year, ethnicity, and year of study.

\section{Predictors}

Self-esteem. Rosenberg's (1965) ten item scale was used to index global self-esteem. Participants indicated their agreement to statements (e.g., "On the whole, I am satisfied with myself") using a scale from zero (strongly disagree) to three (strongly agree). Responses were summed to yield a possible range from zero to 30 with higher scores indicating higher self-esteem. Cronbach's alpha in the present sample was .88 .

Self-compassion. We used Neff's (2003a) 26 item scale for which participants indicated their endorsements of statements (e.g., "I'm kind to myself when I'm experiencing suffering") on a scale from one (almost never) to five (almost always). In line with recommendations (e.g., Neff et al., 2016), we calculated overall scores by averaging responses to all items for a possible range from one to five with higher scores indicating higher self-compassion. In the present sample, Cronbach's alpha was .92.

Self-efficacy. Chen et al.'s (2001) eight item scale was used to index one's general self-efficacy. Participants responded to items (e.g., "I will be able to success- 
fully overcome many challenges") with a scale ranging from one (strongly disagree) to five (strongly agree). Responses were averaged with a possible range from one to five with higher scores indicating more self-efficacy. In the present sample, Cronbach's alpha was .91.

Mindsets. The Mindset Quiz developed from Dweck's (2000) theory ${ }^{1}$ was used to index participants' views of ability (14 items; e.g., "You can always substantially change how intelligent you are") and character (six items; e.g., "You can always change basic things about the kind of person you are"). Participants indicated their responses on a scale from zero (strongly disagree) to four (strongly agree) and items were summed to yield two scores for which higher values represent more growth mindset for ability (possible range from zero to 56; Cronbach's $\alpha=.73$ ) or character (possible range from zero to 24; Cronbach's $\alpha=.62$ ).

\section{Outcomes}

Self-control. To index self-control, we used Tangney et al.'s (2004) 13 item self-report scale. Participants indicated the degree that statements (e.g., "I am good at resisting temptation") reflected how they typically were using a scale from one (not at all) to five (very much). Responses were summed to yield a score that could range from 13 to 65 with higher scores indicating more self-control. Cronbach's alpha in the present sample was 83 .

Persistence. Two items (e.g., "I will often continue to work on something, even after other people have given up") from Steinberg et al. (2012) were used as a direct measure of task persistence. Each item was responded to on a scale from one (false) to four (true) and responses were summed to yield a range from two to eight with higher scores indicating more persistence. In the present sample, Cronbach's alpha was modest at .59.

Academic self-regulation. Geldhof et al.'s (2012) 15 item scale was used to index academic self-regulation. Participants responded to each item (e.g., "It is easy for me to stay focused on my schoolwork") on a scale from one (not at all) to seven (very much) and responses were summed to yield one score that could range from 15 to 105 with higher scores indicating more self-regulation with academics. In the present sample, Cronbach's alpha was .90 .

Emotion regulation. Gross and John's (2003) emotion regulation scale was used to index two regulatory processes: cognitive reappraisal (e.g., "I control my emotions by changing the way I think about the situation I'm in") and emotive suppression (e.g., "I control my emotions by not expressing them"). Participants indicated the extent of agreement with each statement on a scale from one (strongly disagree) to seven (strongly agree). Responses to six items were summed to yield an overall score on cognitive reappraisal that could range from six to 42 (Cronbach's $\alpha=.81$ ) and, responses to four items were summed to yield a possible range from four to 28 for emotive suppression (Cronbach's $\alpha=.75$ ) with higher scores indicating more cognitive reappraisal/emotive suppression.

Mental health. Lovibond and Lovibond's (1995) Depression, Anxiety and Stress Scale-21 items (DASS-21) includes three self-report scales to index three emotional states (depression, anxiety, stress). Each scale comprises seven items (e.g., stress: "I found it hard to wind down") that participants are asked to indicate how much this applies to them over the past week using a scale from zero (did not apply to me at all) to three (applied to me very much or most of the time). Responses for relevant items on each scale were summed and ranged from zero to 21 with higher scores indicating higher levels of each state. In the present sample, Cronbach's alphas were $.91, .85$, and .82 for depression, anxiety, and stress, respectively.

Psychological well-being. Participants completed Diener et al.'s (2009) eight item flourishing scale by indicating their extent of agreement with each statement (e.g., "I lead a purposeful and meaningful life") on a scale from one to seven. Responses were summed to yield a possible range from 15 to 56 with higher scores indicating many psychological strengths and resources. In the present sample, Cronbach's alpha was .90.

Grades. Participants were asked to indicate their willingness for the researchers to collect their term grades for Introductory Psychology and their overall grade point average for the first semester from their course instructors and from a secure database, respectively. One hundred and two students consented for the researchers to access their grades which ranged from zero to 4.3 where $D$ minus corresponds to a grade of 0.7 and each increment of .3 in grade represents an increase in the letter grade (e.g., $1.0=D ; 1.3=D$ plus) for a maximum value of $A$ plus (grade $=4.3$ ). 


\section{Results}

Scores were computed if participants had responded to at least $80 \%$ of the items for each scale and this resulted in no missing data. Background statistics were computed including means, standard deviations, Cronbach's alphas, and correlations. Then, multiple regression analyses were undertaken to examine the unique contributions of each predictor.

\section{Background Analyses}

Because there were five scales used to examine regulatory processes (self-control, persistence, academic self-regulation, cognitive reappraisal, and emotive suppression), we sought to reduce these to a fewer number of variables for analyses. We rescaled the scores on emotive suppression such that higher scores indicated less emotional suppression so that this aligned with the scores on the other variables where high scores indicated more self-control. We undertook a principal components analysis with Varimax rotation with scores on reappraisal, suppression, self-control, persistence, and academic self-regulation. The Kaiser-Meyer-Olkin Test was .57 and Bartlett's test of sphericity was < .001 indicating the data were marginally suitable for factor analysis. Two factors were extracted and accounted for $60.35 \%$ of the variability based on eigenvalues greater than 1.00 and supported by the Scree plot. For the first component, subsequently labeled as general self-control, the loadings were $.78, .67, .81, .25$, and -.11 for self-control, persistence, academic self-regulation, cognitive reappraisal, and emotive suppression, respectively. For the second component, subsequently labeled as emotional control, the loadings were $.15,-.29, .31, .61$, and .81 for self-control, persistence, academic self-regulation, cognitive reappraisal, and emotive suppression, respectively. Scores from scales with loadings greater than .40 were summed to yield two scores and these groupings were supported by Cronbach's alphas of .92 for general self-control (self-control, persistence, and academic self-regulation) and .75 for emotional control (cognitive reappraisal and emotive suppression).

\section{Hypothesis Testing}

We first computed descriptive statistics and bivariate correlations among the predictors: self-esteem, self-compassion, self-efficacy, ability mindsets, and character mindsets as these constructs reflect individual strengths/ resources. As expected, self-compassion, self-esteem, and self-efficacy moderately overlapped whereas these scores showed small positive correlations with ability mindsets and were not related to character mindsets. Thus, scores on character mindsets were excluded from further analyses.

Correlations among the outcome variables are in Table 2. Notable is the finding that all correlations were significant, with the exception of those involving grades. Specifically, both indices of self-control were associated with mental health outcomes; however, course grade and term GPA were positively associated with behavioural self-control (and not emotional control) and both grades were inversely related to depression and anxiety (and not stress).

We next examined the correlations between the predictors and outcomes (Table 3). As expected, self-esteem, self-compassion, and self-efficacy showed similar patterns of relationships with the outcomes whereby they were all significantly related to self-control and psy-

Table 1. Descriptive statistics and correlations among individual difference variables $(N=214)$

\begin{tabular}{llllll}
\hline Variable & Mean $(S D)$ & 1 & 2 & 3 & 4 \\
\hline 1. Self-compassion & $2.73(0.60)$ & & & & \\
2. Self-esteem & $16.98(5.29)$ & $.62^{* *}$ & & \\
3. Self-efficacy & $3.55(0.70)$ & $.40^{* *}$ & $.56^{* *}$ & & \\
4. Ability mindset & $27.04(4.63)$ & $.15^{*}$ & $.16^{*}$ & $.21^{* *}$ & \\
5. Character mindset & $10.72(2.38)$ & -.01 & .12 & $.15^{*}$ & $.51^{* *}$ \\
\hline
\end{tabular}

Note. ${ }^{*}$ indicates $p<.05$ and ${ }^{* *}$ indicates $p<.01$. 
Table 2. Descriptive statistics and correlations among outcome variables $(N=214)$

\begin{tabular}{|c|c|c|c|c|c|c|c|c|}
\hline Variable & Mean (SD) & 1 & 2 & 3 & 4 & 5 & 6 & 7 \\
\hline 1.General self-control & $\begin{array}{c}113 \\
(19.73)\end{array}$ & & & & & & & \\
\hline 2. Emotional control & $\begin{array}{l}43.96 \\
(8.31)\end{array}$ & $.22^{* *}$ & & & & & & \\
\hline 3. Depression & $\begin{array}{c}7.13 \\
(5.44)\end{array}$ & $-.37^{* *}$ & $-.36^{* *}$ & & & & & \\
\hline 4. Anxiety & $\begin{array}{c}7.10 \\
(5.16)\end{array}$ & $-.19^{* *}$ & $-.21^{* *}$ & $.65^{* *}$ & & & & \\
\hline 5. Stress & $\begin{array}{c}8.79 \\
(4.72)\end{array}$ & $-.15^{*}$ & $-.22^{* *}$ & $.62^{* *}$ & $.77^{* *}$ & & & \\
\hline 6. Well-being & $\begin{array}{c}42.86 \\
(7.6)\end{array}$ & $.48^{* *}$ & $.49^{* *}$ & $-.57^{* *}$ & $-.31^{* *}$ & $-.29^{* *}$ & & \\
\hline 7. Course grade & $\begin{array}{c}3.18 \\
(1.02)\end{array}$ & $.45^{* *}$ & .07 & $-.34^{* *}$ & $-.21^{*}$ & -.12 & .12 & \\
\hline 8. Term GPA & $\begin{array}{c}2.92 \\
(0.94)\end{array}$ & $.41^{* *}$ & .02 & $-.31^{* *}$ & $-.20^{*}$ & -.11 & .09 & $.86^{* *}$ \\
\hline
\end{tabular}

Note. ${ }^{*}$ indicates $p<.05$ and ${ }^{* *}$ indicates $p<.01$. Correlations involving course grade and term GPA are based on 102 observations.

Table 3. Correlations between predictor and outcome variables $N=214$

\begin{tabular}{lcccccccc}
\hline \multicolumn{7}{c}{$\begin{array}{c}\text { Outcome Variables } \\
\text { (Mean, SD) }\end{array}$} \\
\hline Predictor & $\begin{array}{c}\text { General } \\
\text { self-control }\end{array}$ & $\begin{array}{c}\text { Emotional } \\
\text { control }\end{array}$ & Depression & Anxiety & Stress & Well-being & $\begin{array}{c}\text { Course } \\
\text { GPA }\end{array}$ & Term GPA \\
& $(113$, & $(43.96$, & $(7.13$, & $(7.10$, & $(8.79$, & $(42.86$, & $(3.18$, & $(2.92,$. \\
& $19.73)$ & $8.31)$ & $5.44)$ & $5.16)$ & $4.72)$ & $7.6)$ & $1.02)$ & $94)$ \\
Self-esteem & $.36^{* *}$ & $.42^{* *}$ & $-.67^{* *}$ & $-.47^{* *}$ & $-.38^{* *}$ & $.71^{* *}$ & .19 & .19 \\
Self-compassion & $.23^{* *}$ & $.50^{* *}$ & $-.52^{* *}$ & $-.46^{* *}$ & $-.51^{* *}$ & $.51^{* *}$ & .15 & .06 \\
Self-efficacy & $.48^{* *}$ & $.24^{* *}$ & $-.39^{* *}$ & $-.28^{* *}$ & $-.24^{* *}$ & $.58^{* *}$ & $.28^{* *}$ & $.24^{*}$ \\
Ability Mindset & $.29^{* *}$ & $.24^{* *}$ & $-.20^{* *}$ & -.04 & -.10 & $.29^{* *}$ & .15 & .04 \\
\hline
\end{tabular}

Note. ${ }^{*}$ indicates $p<.05$ and ${ }^{* *}$ indicates $p<.01$. Correlations for course GPA and term GPA are based on 102 observations.

chological well-being. However, only self-efficacy was related to course and term GPA. Ability mindsets related to self-control and two of the four outcomes related to psychological well-being (depression and flourishing) and not significantly related to GPA.

The relationships uncovered between the predictors and outcomes provide support for undertaking multiple regression analyses to examine the unique variance accounted for by the predictors. We specified multiple regression models in which the predictors of self-esteem, self-compassion, self-efficacy, and ability mindsets were entered simultaneously for the prediction of each outcome. Table 4 includes the results for all eight multiple regression analyses including those for the outcomes 
Table 4. Predicting self-regulation, psychological well-being, and grades from individual differences $(N=214)$

\begin{tabular}{lcccccc}
\hline Outcome & $\begin{array}{c}\text { Self-esteem } \\
b(S E) \beta\end{array}$ & $\begin{array}{c}\text { Self-compassion } \\
b(S E) \beta\end{array}$ & $\begin{array}{c}\text { Self-efficacy } \\
b(S E) \beta\end{array}$ & $\begin{array}{c}\text { Mindsets } \\
b(S E) \beta\end{array}$ & $F$ & $R^{2}$ \\
\hline $\begin{array}{l}\text { General self- } \\
\text { control }\end{array}$ & $0.55(0.31) .15$ & $-1.11(2.47)-.03$ & $10.41(2.02)^{* *} .37$ & $0.81(0.26)^{* *} .19$ & 20.03 & $.28^{* *}$ \\
$\begin{array}{l}\text { Emotional } \\
\text { control }\end{array}$ & $0.30(0.13)^{*} .19$ & $5.29(1.03)^{* *} .38$ & $-0.66(0.84)-.06$ & $0.30(0.11)^{* *} .17$ & 22.39 & $.30^{* *}$ \\
Depression & $-0.57(0.07)^{* *}-.55$ & $-1.56(0.58)^{* *}-.17$ & $0.05(0.48) .01$ & $-0.1(0.06)-.08$ & 47.07 & $.47^{* *}$ \\
Anxiety & $-0.29(0.08)^{* *}-.30$ & $-2.37(0.65)^{* *}-.28$ & $-0.12(0.53)-.02$ & $0.06(0.07) .06$ & 19.38 & $.27^{* *}$ \\
Stress & $-0.09(0.07)-.10$ & $-3.53(0.59)^{* *}-.45$ & $<0.01(0.49)<.01$ & $-0.02(0.06)-.02$ & 19.26 & $.27^{* *}$ \\
Well-being & $0.73(0.09)^{* *} .51$ & $1.02(0.73) .08$ & $2.53(0.60)^{* *} .23$ & $0.24(0.08)^{* *} .15$ & 71.64 & $.58^{* *}$ \\
Course grade & $<.01(0.03)-.01$ & $.07(.20) .04$ & $.34(.17)^{* *} .25$ & $0.02(0.02) .09$ & 2.37 & $.09+$ \\
GPA & $0.02(0.02) .11$ & $-.12(0.19)-.08$ & $0.26(0.16) .21^{\wedge}$ & $-.01(0.02)-.03$ & 1.69 & .07 \\
\hline
\end{tabular}

Note. ${ }^{*}$ indicates $p<.05^{* *}$ indicates $p<.01+$ indicates $p=.058$. Multiple regression models for course grade and GPA were based on 102 participants.

of self-control (general and emotional), psychological wellbeing (depression, anxiety, stress, well-being), and grades (course grade and term GPA). All assumptions were met. There were no multivariate outliers as all standardized residuals ranged between -3 and +3 and data were normally distributed based on probability plots. Tolerance levels were all greater than .51, indicating multi-collinearity was not an issue.

As seen in Table 4, self-efficacy and ability mindsets both predicted general self-control whereas neither self-compassion nor self-esteem accounted for any unique variance. In contrast, self-esteem and self-compassion each uniquely contributed to the prediction of emotional control, depression, and anxiety whereas self-efficacy failed to account for any variance in these outcomes and mindsets contributed to the prediction of emotional control only. Furthermore, self-compassion predicted less stress whereas self-esteem did not, and self-esteem predicted flourishing whereas self-compassion did not. In line with the bivariate correlations, only self-efficacy was a significant predictor of course grade and marginally significant for overall GPA.

\section{Discussion}

The purpose of this study was to investigate the unique contributions of individual difference variables known to predict outcomes among university students. Through self-reports, we examined self-esteem, self-compassion, self-efficacy, and mindsets as predictors of self-control, mental health, and grades.

Bivariate correlations showed that the predictors substantially overlapped ranging from small (e.g., self-compassion and ability mindset) to large (e.g., self-compassion and self-esteem). Thus, much like previous research demonstrating overlap (e.g., de Souza \& Hutz, 2016; Neff et al., 2005; Neff \& Vonk, 2009; Passmore et al., 2018), the results highlight the utility of examining their unique contributions in a variety of outcomes. To the best of our knowledge, no research to date has explored the relative contributions of these overlapping constructs for predicting outcomes among university students.

Whereas the bivariate correlations between the predictors and the outcomes were largely as expected, key to our study were the results of the multiple regression analyses. Specifically, we first showed that self-efficacy and mindsets each significantly predicted general self-control whereas self-esteem and self-compassion did not. Recall that general self-control encompassed items that targeted behaviours for resisting temptation, persisting on tasks, and completing academic work. Because self-efficacy captures the beliefs that one has in their own abilities (Bandura, 1977) and mindsets capture 
the beliefs about the malleability of those abilities (Yeager \& Dweck, 2012), these results demonstrate that beliefs were more predictive than attitudes towards one's self. Students who believe that they can successfully meet academic challenges and who also believe that learning is acquired through effort are those who regulate their behaviours. In contrast, having high positive regard for one's self and/or responding to one's self with compassion was not associated with self-regulation as indexed in the present study. Whereas a large literature attests to the benefits of self-compassion for psychological health, including emotion regulation, few studies have examined its relationship to behavioural regulation. In their meta-analysis, Biber and Ellis (2019) found that self-compassion interventions were effective for improving health behaviours (i.e., eating, smoking, exercise, self-care) across seven studies. Biber and Ellis (2019) argued that self-compassion interventions may be particularly helpful for those who are self-critical or harsh towards themselves regarding their health behaviours. In the present study, we did not identify students who judged their academic performance negatively, making it difficult to discern if self-compassion provides benefits for specific groups of students who may experience more emotional impact regarding their academics.

Importantly, both self-efficacy and growth mindsets can be fostered through interventions. Interventions aimed at increasing self-efficacy target specific domains (e.g., Unrau et al., 2018) and typically incorporate the sources of self-efficacy outlined by Bandura (1997) to strengthen one's confidence in their abilities. Research also demonstrates that growth mindsets can be fostered with targeted interventions with subsequent improvements in academic outcomes (e.g., Blackwell et al., 2007; Yeager et al., 2016).

For the outcome of emotional control, in addition to growth mindsets, self-esteem and self-compassion independently predicted more engagement in strategies intended to regulate one's emotions. Moreover, self-esteem and self-compassion were the only significant predictors of depression and anxiety, each accounting for a unique portion of the variability. The lack of a relationship between self-efficacy and mindsets with aspects of psychological health may be explained by the focus of the measures used in the present study. Specifically, both self-efficacy and mindsets were limited to the academic setting asking respondents to consider their schoolwork or their learning. Research using measures to index people's beliefs in the context of mental health may uncover relationships not found in the present study.

Overall, the results for the mental health outcomes are in line with past research (e.g., MacBeth \& Gumley, 2012; Sowislo \& Orth, 2013) highlighting the value of self-attitudes for emotional well-being. Thus, interventions targeting such attitudes would contribute to likely reduce mental health concerns on campuses. A sizable literature now exists establishing the effectiveness of self-compassion interventions (e.g., Neff \& Germer, 2013) that result in increases in mood, mindfulness, compassion for others, life satisfaction, and happiness, as well as corresponding decreases in anxiety, depression and stress (Finlay-Jones et al., 2017; Neff \& Germer, 2013; Shapiro et al., 2005).

Although in the present study self-compassion was the only predictor that did not significantly contribute to the prediction of general well-being (i.e., flourishing), this may be explained by the level of abstraction of the predictors and outcome. When predictors and criteria are matched in terms of whether they are general or specific, the relationships are likely more accurate (e.g., Swann et al., 2007). Both self-esteem and self-efficacy were general indices as was the outcome of flourishing, but not all predictors and criteria were well matched. For example, self-compassion may be a less general attitude insofar that it is most beneficial when one focuses on inadequacies or failures. Certainly, when using these same constructs for predicting the specific outcome of grades, most failed to do so.

The results for grades were unexpected because only self-efficacy predicted course grade and there were no significant predictors for overall GPA. Thus, it appears that having confidence in one's ability to obtain a specific grade in a course may translate to behaviours that facilitate achievement of such a goal. In contrast, holding a positive view of one's self may not alter goal directed behaviour. Yet the lack of results for grades may also be explained by the fact that grades are multi-determined and do not only reflect one's ability or aspects of one's self. Furthermore, data collection occurred in the first month of the first semester of the academic year with grades collected at the end of term. It is possible that there were changes in the predictors over the time span. Future researchers should consider multiple assessments of the constructs of interest to determine changes. 
There are at least three limitations associated with the present study. First, we relied on self-report measures to index all variables (except for grades). Although we controlled for careless responding by including attention checking questions, the use of self-reports may have predisposed participants to respond in a socially desirable way. Researchers may want to include an index of social desirability in future investigations to control for such biases. Second, the cross-sectional nature of the data only allows us to speculate on the causal directions of the variables studied. Although our ordering of the variables was in line with theory and past research, our results do not preclude reciprocal relationships. However, the relationships uncovered may contribute to identifying potential pathways. For example, self-compassion may have an indirect effect on grades (i.e., actual performance) via mental health. Whereas we did not explore such models because of the number of analyses already undertaken and the limited sample size, only longitudinal studies would support causal mediational relationships. Finally, although we targeted a first-year course, not all students who participated were in their first year. It seems likely that students develop many of the attributes we were interested in as they progress through their studies.

The results here bring good news for those institutions already targeting mental health and academic behaviours and those that have adopted interventions related to the variables studied here. We believe that in addition to showing the unique contributions of key predictors of student outcomes, we have highlighted the importance of considering multiple outcomes. We propose that a focus on student outcomes should not be limited to academics but include mental health and psychological well-being. Moreover, we suggest that researchers continue to explore the individual contributions of our chosen predictors in other outcomes relevant for university students such as commitment to education. Additionally, there may be other predictors not included here that are equally important for success in university.

To offer definitive recommendations based on our results would be premature. However, we can suggest that, based on past literature and our results, self-compassion and beliefs (both self-efficacy and mindsets) have complementary (vs. competing) roles in outcomes for university students. Specifically, increasing one's belief in their ability and promoting growth mindsets are routes to behavioural strategies that contribute to aca- demic success and, in contrast, fostering self-compassionate attitudes may be an effective avenue for alleviating mental health concerns.

\section{References}

Adams, T. B., Wharton, C. M., Quilter, L., \& Hirsch, T. (2008). The association between mental health and acute infectious illness among a national sample of 18- to 24-year-old college students. Journal of American College Health, 56(6), 657-664. https:/l doi.org/10.3200/JACH.56.6.657-664

Allen, A. B., \& Leary, M. R. (2010). Self-compassion, stress, and coping. Social and Personality Psychology Compass, 4(2), 107-118. https://doi. org/10.1111/j.1751-9004.2009.00246.x

Andrews, B., \& Wilding, J. M. (2004). The relation of depression and anxiety to life-stress and achievement in students. British Journal of Psychology, 95(4), 509-521. https://doi. org/10.1348/0007126042369802

Anson, O., Bernstein, J., \& Hobfoll, S. E. (1984). Anxiety and performance in two ego threatening situations. Journal of Personality Assessment, 48(2), 168-172. https://doi.org/10.1207/s15327752jpa4802 11

Bandura, A. (1977). Self-efficacy: Toward a unifying theory of behavioral change. Psychological Review, 84(2), 191-215. https://doi.org/10.1037/0033295X.84.2.191

Bandura, A. (1997). Self-efficacy: The exercise of self-control. W. H. Freeman.

Baumeister, R. F., Campbell, J. D., Krueger, J. I., \& Vohs, K. D. (2003). Does high self-esteem cause better performance, interpersonal success, happiness, or healthier lifestyles? Psychological Science in the Public Interest, 4(1), 1-44. https://doi. org/10.1111/1529-1006.01431

Bayram, N., \& Bilgel, N. (2008). The prevalence and socio-demographic correlations of depression, anxiety and stress among a group of university students. Social Psychiatry and Psychiatric Epidemiology, 43(8), 667-672. https://doi.org/10.1007/s00127-008$\underline{0345-x}$ 
Biber, D. D., \& Ellis, R. (2019). The effect of self-compassion on the self-regulation of health behaviors: A systematic review. Journal of Health Psychology, 24(4), 2060-2071. https://doi. org/10.1177/1359105317713361

Blackwell, L. S., Trzesniewski, K. H., \& Dweck, C. S. (2007). Implicit theories of intelligence predict achievement across an adolescent transition: A longitudinal study and an intervention. Child Development, 78(1), 246-263. https://doi.org/10.1111/j.14678624.2007.00995.x

Bostwick K. C. P., Collie, R. J., Martin, A. J., \& Durksen, T. L. (2017). Students' growth mindsets, goals, and academic outcomes in mathematics. Zeitschrift für Psychologie, 225(2), 107-116. https://doi. org/10.1027/2151-2604/a000287

Carver, C. S., \& Scheier, M. F. (2011). Self-regulation of action and affect. In R. F. Baumeister \& K. D. Vohs (Eds.), Handbook of self-regulation: Research, theory, and applications (2nd ed., pp. 3-21). Guilford Press.

Chen, G., Gully, S. M., \& Eden, D. (2001). Validation of a new general self-efficacy scale. Organizational Research Methods, 4(1), 62-83. https://doi. org/10.1177/109442810141004

Claro, S., Paunesku, D., \& Dweck, C. S. (2016). Growth mindset tempers the effects of poverty on academic achievement. PNAS, 113(31), 8664-8668. https:// doi.org/10.1073/pnas.1608207113

Crocker, J., \& Park, L. E. (2004). The costly pursuit of self-esteem. Psychological Bulletin, 130(3), 392414. https://doi.org/10.1037/0033-2909.130.3.392

de Ridder, D. T. D., Lensvelt-Mulders, G., Finkenauer, C., Stok, F. M., \& Baumeister, R. F. (2012). Taking stock of self-control: A meta-analysis of how trait self-control relates to a wide range of behaviors. Personality and Social Psychology Review, 16(1), 76-99. https://doi.org/10.1177/1088868311418749

de Souza, L. K., \& Hutz, C. S. (2016). Self-compassion in relation to self-esteem, self-efficacy and demographical aspects. Paideia, 26(64), 181-188. https:ll doi.org/10.1590/1982-43272664201604

Dey, I. (2018). Class attendance and academic perfor- mance: A subgroup analysis. International Review of Economics Education, 28, 29-40. https://doi. org/10.1016/j.iree.2018.03.003

Diener, E., Wirtz, D., Tov, W., Kim-Prieto, C., Choi, D., Oishi, S., \& Biswas-Diener, R. (2009). New measures of well-being: Flourishing and positive and negative feelings. Social Indicators Research, 39, 247-266. https://doi.org/10.1007/s11205-009-9493-y

Duckworth, A. L., \& Seligman, M. E. P. (2005). Self-discipline outdoes IQ in predicting academic performance of adolescents. Psychological Science, 16(12), 939-944. https://doi.org/10.1111/j.14679280.2005.01641.x

Dweck, C. S. (2000). Mindsets Questionnaire. [Measurement instrument]. https://osf.io/pjwgs/

Dweck, C. S., \& Leggett, E. L. (1988). A social-cognitive approach to motivation and personality. Psychological Review, 95(2), 256-273. https://doi. org/10.1037/0033-295X.95.2.256

Finlay-Jones, A., Kane, R., \& Rees, C. (2017). Self-compassion online: A pilot study of an internet-based self-compassion cultivation program for psychology trainees. Journal of Clinical Psychology, 73(7), 797-816. https://doi.org/10.1002/jclp.22375

Geldhof, J., Little, T. S., \& Hawley, P. H. (2012). Two measures of self-regulation for young adults and late adolescents in the academic and social domains. International Journal of Behavioral Development, 36(6), 476-488. https://doi. org/10.1177/0165025412462153

Gross, J. J., \& John, O. P. (2003). Individual differences in two emotion regulation processes: Implications for affect, relationships, and well-being. Journal of Personality and Social Psychology, 85(2), 348-362. https://doi.org/10.1037/0022-3514.85.2.348

Hjorth, C. F., Bilgrav, L., Frandsen, S. L., Overgaard, C., Torp-Pedersen, C., Nielsen, B., \& Boggild, H. (2016). Mental health and school dropout across educational levels and genders: A 4.8-year follow-up study. BMC Public Health, 16(1), 1-12. https://doi. org/10.1186/s12889-016-3622-8

Hong, Y., Chiu, C., Dweck, C. S., Lin, D. M., \& Wan, W. (1999). Implicit theories, attributions, and coping: A 
meaning system approach. Journal of Personality and Social Psychology, 77(3), 588-599. https://doi. org/10.1037/0022-3514.77.3.588

Hysenbegasi, A., Hass, S. L., Rowland, C. R. (2005). The impact of depression on the academic productivity of university students. The Journal of Mental Health Policy and Economics, 8(3), 141-151.

Ibrahim, A. K., Kelly, S. J., Adams, C. E., \& Glazbrook, C. (2013). A systematic review of studies of depression prevalence in university students. Journal of Psychiatric Research, 47(3), 391-400. https://doi. org/10.1016/j.jpsychires.2012.11.015

Lovibond, S. H., \& Lovibond, P. F. (1995). Manual for the depression anxiety \& stress scales (2nd ed.). Psychology Foundation.

Maritime Provinces Higher Education Commission. (2018). Student progression in the Maritime University System: Persistence and graduation, May 2018 Statistical tables and methodology. http://www. mphec.ca/media/168264/PerstGradTables2018.pdf

MacBeth, A., \& Gumley, A. (2012). Exploring compassion: A meta-analysis of the association between self-compassion and psychopathology. Clinical Psychology Review, 32(6), 545-552. https://doi. org/10.1016/j.cpr.2012.06.003

Misra, R., \& McKean, M. (2000). College students' academic stress and its relation to their anxiety, time management, and leisure satisfaction. American Journal of Health Studies, 16(1), 41-51.

Moulton, K. D., Brown, S. D., \& Lent, R. W. (1991). Relation of self-efficacy beliefs to academic outcomes: A meta-analytic investigation. Journal of Counseling Psychology, 38(1), 30-38. https://doi. org/10.1037//0022-0167.38.1.30

Neff, K. D. (2003a). Development and validation of a scale to measure self-compassion. Self and Identity, 2(3), 223-250. https://doi. org/10.1080/15298860309027

Neff, K. (2003b). Self-compassion: An alternative conceptualization of a healthy attitude toward oneself. Self and Identity, 2(2), 85-101. https://doi. org/10.1080/15298860309032
Neff, K. D., \& Germer, C. K. (2013). A pilot study and randomized controlled trial of the mindful self-compassion program: A pilot and randomized trial of MSC program. Journal of Clinical Psychology, 69(1), 28-44. https://doi.org/10.1002/jclp.21923

Neff, K. D., Hsieh, Y., Dejtterat, K. (2005). Self-compassion, achievement goals, and coping with academic failure. Self and Identity, 4(3), 262-287. https://doi. org/10.1080/13576500444000317

Neff, K. D., \& Vonk, R. (2009). Self-compassion versus global self-esteem: Two different ways of relating to oneself. Journal of Personality, 77(1), 23-50. https:ll doi.org/10.1111/j.1467-6494.2008.00537.x

Neff, K. D., Whittaker, T. A., \& Karl. A. (2016). Examining the factor structure of the self-compassion scale in four distinct populations: Is the use of a total scale score justified? Journal of Personality Assessment, 99(6), 596-607. https://doi.org/10.1080/00223891.2 016.1269334

Passmore, H., Howell, A. J., \& Holder, M. D. (2018). Positioning implicit theories of well-being within a positivity framework. Journal of Happiness Studies, 19(8), 2445-2463. https://doi.org/10.1007/s10902017-9934-2

Pearson, C., Janz, T., \& Ali, J. (2013). Health at a Glance: Mental and substance use disorders in Canada (Statistics Canada Catalogue no. 82-624X). Statistics Canada. https://www150.statcan.gc.cal n1/pub/82-624-x/2013001/article/11855-eng.htm

Razali, S. N. A. M., Rusiman, M. S., Gan, W. S., \& Arbin, N. (2017). The impact of time management on students' academic achievement. Journal of Physics: Conference Series, 995(1). https://iopscience.iop. org/article/10.1088/1742-6596/995/1/012042

Robbins, S. B., Lauver, K., Le, H., Davis, D., Langley, R., \& Carlstrom, A. (2004). Do psychosocial and study skill factors predict college outcomes? A meta-analysis. Psychological Bulletin, 130(2), 261-288. https:/l doi.org/10.1037/0033-2909.130.2.261

Romero, C., Master, A., Paunesku, D., Dweck, C. S., \& Gross, J. J. (2014). Academic and emotional functioning in middle school: The role of implicit theories. Emotion, 14(2), 227-234. https://doi. 


\section{org/10.1037/a0035490}

Rosenberg, M. (1965). Society and the adolescent self-image. Princeton University Press.

Sanitchai, P., \& Thomas, D. (2018). The relationship of active learning and academic achievement among provincial university students in Thailand. Association of Private Higher Education Institutions of Thailand, 7, 47-61.

Shapiro, S. L., Astin, J. A., Bishop, S. R., \& Cordova, M. (2005). Mindfulness-based stress reduction for health care professionals: Results from a randomized trial. International Journal of Stress Management, 12(2), 164-176. https://doi.org/10.1037/1072$\underline{5245.12 .2 .164}$

Sowislo, J. F., \& Orth, U. (2013). Does low self-esteem predict depression and anxiety? A meta-analysis of longitudinal studies. Psychological Bulletin, 139(1), 213-240. https://doi.org/10.1037/a0028931

Sriram, R. (2014). Rethinking intelligence: The role of mindset in promoting success for academically high-risk students. Journal of College Student Retention, 15(4), 515-536.

Steel, P. (2007). The nature of procrastination: A meta-analytic and theoretical review of quintessential self-regulatory failure. Psychological Bulletin, 133(1), 65-94. https://doi.org/10.1037/00332909.133.1.65

Steinberg, M. L., Williams, J. M., Gandhi, K. K., Foulds, J., Epstein, E. E., \& Brandon, T. H. (2012). Task persistence predicts smoking cessation in smokers with and without schizophrenia. Psychology of Addictive Behaviors, 26(4), 850-858. https://doi. org/10.1037/a0028375

Swann Jr., W. B., Chang-Schneider, C., \& McClarty, K. L. (2007). Do people's self-views matter? Self-concept and self-esteem in everyday life. American Psychologist, 62(2), 84-94. https://doi.org/10.1037/0003066X.62.2.84

Tangney, J. P., Baumeister, R. F., \& Boone, A. L. (2004). High self-control predicts good adjustment, less pathology, better grades, and interpersonal success. Journal of Personality, 72(2), 271-322. https://doi. org/10.1111/j.0022-3506.2004.00263.x
Unrau, N. J., Rueda, R., Son, E., Polanin, J. R., Lundeen, R. J., \& Muraszewski, A. K. (2018). Can reading self-efficacy be modified? A meta-analysis of the impact of interventions on reading self-efficacy. Review of Education Research, 88(2), 167-204. https://doi.org/10.3102/0034654317743199

Vohs, K. D., \& Baumeister, R. F. (2004). Understanding self-regulation: An introduction. In R. F. Baumeister \& K. D. Vohs (Eds.), Handbook of self-regulation: Research, theory, and applications (pp. 1-9). Guilford Press.

Weisskirch, R. S. (2018). Grit, self-esteem, learning strategies and attitudes and estimated and achieved course grades among college students. Current Psychology, 37(1), 21-27. https://doi.org/10.1007/ s12144-016-9485-4

Wilks, S. E., \& Spivey, C. A. (2010). Resilience in undergraduate social work students: Social support and adjustment to academic stress. Social Work Education, 29(3), 276-288. https://doi. org/10.1080/02615470902912243

Yeager, D. S., \& Dweck, C. S. (2012). Mindsets that promote resilience: When students believe that personal characteristics can be developed. Educational Psychologist, 47, 302-314. https://doi.org/10.1080/0 $\underline{0461520.2012 .722805}$

Yeager, D. S., Romero, C., Paunesku, D., Hulleman, C. S., Schneider, B., Hinojosa, C., Lee, H. Y., O'Brien, J., Flint, K., Roberts, A., Trott, J., Greene, D., Walton, G. M., \& Dweck, C. S. (2016). Using design thinking to improve psychological interventions: The case of the growth mindset during the transition to high school. Journal of Education Psychology, 108(3), 374-391. https://doi.org/10.1037/ edu0000098

Zander, L., Brouwer, J., Jansen, E., Crayen, C., \& Hannover, B. (2018). Academic self-efficacy, growth mindsets, and university students' integration in academic and social support networks. Learning and Individual Differences, 62, 98-107. https://doi. org/10.1016/j.lindif.2018.01.012

Zeigler-Hill, V., Li, H., Masri, J., Smith, A., Vonk, J., Madson, M. B., \& Zhang, Q. (2013). Self-esteem instability and academic outcomes in American 
and Chinese college students. Journal of Research in Personality, 47(5), 455-463. https://doi. org/10.1016/j.jp.2013.03.010

Zessin, U., Dickhauser, O., \& Garbade, S. (2015). The relationship between self-compassion and well-being: A meta-analysis. Applied Psychology: Health and Well-Being, 7(3), 340-364. https://doi. org/10.1111/aphw.12051

\section{Contact Information}

Louise Wasylkiw

Iwasylkiw@mta.ca

\section{Notes}

1 Available from http://homepages.math.uic.edu/ bshipleyl 